\title{
Using microfluidic set-up to determine the adsorption rate of $S$. Pasteurii bacteria on sandstone
}

\author{
Tom Marzin • Brice Desvages • Adama \\ Creppy - Louis Lépine • Annette \\ Esnault-Filet • Harold Auradou ${ }^{\star}$.
}

the date of receipt and acceptance should be inserted later

\begin{abstract}
Microbial-induced carbonate precipitation (MICP) in porous media is a two-step procedure: first the suspension of bacteria is injected and some of the bacteria get stuck on the grains. The second stage consists in the injection of a calcifying solution that triggers the calcite precipitation and creates a calcite shell around the bacteria. In the present article, we describe a novel method to measure the adhesion rate of $S$. Pasteurii bacteria on sandstone and that, additionaly, allows to obtain information about local position of the calcite crystals on the sandstone grains. The method is based on the detection of the crystals developed on grains placed inside a microfluidic cell. The potential of the technique was evaluated and demonstrated by studying the influence of the injection time and ionic strength on the adhesion rate and on the spatial distribution of the crystals. The values of the adhesion rates are in good agreement with values determined using column experiments. We find, for example, an increase of the adhesion rate with the $\mathrm{NaCl}$ in solution, with a rate of the order of $0.005 \mathrm{~min}^{-1}$ for a concentration of 3 gram per liter
\end{abstract}

\footnotetext{
* Corresponding Author
}

Tom Marzin

Université Paris-Saclay, CNRS, FAST, 91405, Orsay, France

Brice Desvages

Soletanche-Bachy, 280 avenue Napoléon Bonaparte - 92500 Rueil-Malmaison (France)

Adama Creppy

Université Paris-Saclay, CNRS, FAST, 91405, Orsay, France

Louis Lépine

Soletanche-Bachy, 280 avenue Napoléon Bonaparte - 92500 Rueil-Malmaison (France)

Annette Esnault-Filet

Soletanche-Bachy, 280 avenue Napoléon Bonaparte - 92500 Rueil-Malmaison (France)

E-mail: Annette.ESNAULT@soletanche-bachy.com

Harold Auradou

Université Paris-Saclay, CNRS, FAST, 91405, Orsay, France.

E-mail: harold.auradou@universite-paris-saclay.fr 
with a maximum of $0.03 \mathrm{~min}^{-1}$ for experiments realized with a salt concentration of $20 \mathrm{~g} / \mathrm{L}$. Our work shows it is possible to use small volumes of fluid to determine quantities accurately, such as adhesion rate or crystals spatial repartition, avoiding the waste of a large quantity of fluids. The method also opens the possibility to screen different fluid compositions and flow conditions to optimize the MICP process.

Keywords Bacteria · Adhesion - Biocalcification - soil reinforcement . Bio-mediated soil improvement · S. Pasteurii · Adhesion rate · Filtration · Urease activity

PACS $47.56 .+\mathrm{r}$

\section{Introduction}

Because of its environmental implications and industrial applications, microbialinduced carbonate precipitation (MICP) is an area of intense research. MICP is, for instance, currently used to improve the geotechnical properties of underground through the precipitation of calcite at soil particle contact [1] or to repair and ciment cracks [2]. MICP has also been proposed as a novel and environmentally-friendly strategy for the conservation of deteriorated ornamental stone [3]. The basic idea of the process is to take advantage of the enzyme contained in the bacterial cells to catalyze the hydrolysis of urea and to produce ammonium and carbonate ions, that precipitate in the presence of dissolved calciums ions under the form of calcium carbonate crystals.

For the reinforcement of soil, the strategy is to induce the formation of the crystals on the grains of the ground over a controlled distance. The surface coating of the grains and/or the creation of bridges between the grains improve the mechanical properties of the underground without affecting significantly its permeability [1].

Step one of the MICP process consists of the injection of the suspension of bacteria in the soil. The physicochemical properties of the suspension and the flow velocity have then to be adjusted as function of the volume to be reinforced. In practice the distribution of bacteria is modelled by the theory of filtration originally derived for colloid particles. In this model, the transport of bacteria in an homogeneous porous media of porosity $\theta$ is described by advection-dispersion equations, eventually modified to include mass exchange with the grains through phenomenological coefficients. In MICP applications, biological parameters such as growth by cell division or death by predation or lysis of bacteria, are often neglected. Furthermore, the mass exchange is modelled by a first-order kinetic deposition term [4-6] and possible desorption is neglected. Under those conditions, the concentration of bacteria $c(x, t)$ per unit of volume along the flow direction $x$ and the concentration of bacteria retained $s(x, t)$ at position $x$ is given by a one-dimensional advection-dispersion 
equation $[5,7,6,8,9]$ :

$$
\begin{array}{r}
\frac{\partial c}{\partial t}+\frac{1}{\theta} \frac{\partial J_{x}}{\partial x}=-\kappa^{+} c, \\
\frac{\partial s}{\partial t}=\frac{\theta}{1-\theta} \kappa^{+} c
\end{array}
$$

Where $J_{x}$ is the flux of bacteria due to particle advection, hydrodynamic dispersion and molecular diffusion and $\kappa^{+}$the rate of deposition. In the case of a continuous injection of a suspension of bacteria at concentration $c_{0}$ at an average fluid velocity $v_{f}$, the concentrations $c(x)$ and $s(x, t)$ are:

$$
\begin{aligned}
& c(x)=c_{0} \exp \left(-\frac{\kappa^{+} \theta x}{v_{f}}\right), \\
& s(x, t)=\frac{\theta}{1-\theta} c(x) t \kappa^{+}
\end{aligned}
$$

The first equation shows that the number of bacteria in the fluid decreases exponentially with the distance from the inlet In this model, the number of fixed bacteria increased linearly with time. Previous studies have highlighted the key role played by the ionic strength on the rate of fixation of the bacteria on the grains [10]. The salinities of the solutions flushed are then an important parameter that has to be considered with great care in the MICP optimization strategy $[9,11]$. After the fixing step, a certain volume of calcifying solution is injected and left in the soil from several minutes to several hours (Step 4 in Fig.1). This step can be repeated several times according to the strategy chosen [11].

In practice, column or field scale experiments are the actual methods used to determine the effect of each parameter on the adhesion of S. Pasterii [11]. In column experiments, the absorption rate is obtained by measuring the ratio of the bacterial concentrations measured, respectively, at the inlet and outlet of the sample of porosity $\theta$. The absorption rate for an imposed velocity $v_{f}$ is then deduced from Eq.3. Bacteria adhesion on surface is also an important issue in other areas like research in health and microbiology. These fields have taken advantage of the development of microfluidics to obtain a controlled environment allowing for the direct observation of microorganisms on surfaces. This technique has, for instance, permitted to obtain a clear understanding of the initial adhesion mechanism. Modifying the surface chemistry and geometry has also enabled the visualization of their influence on the adhesion [15], development [17] and on organization [18] of bacterial colony. More recently, Bai and coworkers [12] demonstrated that set-ups combining microfluidic chips and microscopy can give important insight on the MICP mechanism in biofilm made by Pseudomonas aeruginosa. In order to get insight into the micro-scale processes governing adhesion in more complex geometries, transparent micromodels of porous media were also used to study the mechanism of surface deposition of small particles on grains [16]. By changing the surface roughness 
of the obstacles placed in the micromodel, they pointed out the role of the roughness on the colloid capture. To be as precise and realistic as possible in the determination of physical parameters that would be used in field models, it is thus important to be as close as possible to the field. By performing experiments with grains collected in the field, we kept unchanged factors like surface roughness and surface charge. At the same time, we will take advantage of the possibility offered by the combined use of microfluidic and microscopy to visualize MICP at the pore scale.

Our study focused on two main issues: the influence of the time of injection and of the ionic strength on the adhesion rate of $S$. Pasteurii on sandstone and on the localisation of the crystals formed by MICP on sandstone. We also compare our results with those obtained with column experiments. We finally discuss the new possibilities offered by our technique compared to those reported in the literature.

\section{Experimental set-up and procedure}

The experimental set-up and the procedure used to study and characterize MICP in porous media are illustrated in Fig.1, and a more detailed view of the geometry of the flow cell is provided in the Online Resource 1. It consists of a slot of length $\mathrm{L}=35 \mathrm{~mm}$, depth $100 \mu \mathrm{m}$ and width of $\mathrm{w}=5 \mathrm{~mm}$ was, milled in a Plexiglas plate. The milling was done using a computer-controlled micromilling machine (Roland ${ }^{\circledR}$ MDX 540). Micromilling is an alternative method to most common microfabrication methods like injection molding, hot embossing, or stereolithography to create microfluidic devices [13]. One of the main advantages is the ability to fabricate a transparent object with microscale shapes directly from a three-dimensional (3D) computer-aided design (CAD) model with a very good vertical resolution (here $10 \mu \mathrm{m}$ ) over horizontal distance of several centimeters with good precision [14]. Two outlets were drilled on both sides of the channel to allow the fluid to flow in the channel. The diameters of the inlet and outlet were respectively 10 and $6.25 \mathrm{~mm}$.

Fontainebleau sandstone grains were then sieved and grains between 80 and $100 \mu \mathrm{m}$ were collected. We used a MorphologiG3 Malvern ${ }^{\circledR}$ analyzer to obtain the size and shapes of the grains. The grains were dusted on a glass slide placed under a microscope. Pictures using a low magnification objective (i.e. x10) were then automatically taken and analyzed. Fig.2 shows the distribution of the diameters of particle obtained with that method. The corresponding average radius of the grains (assuming that the grains are circular) is $63 \mu \mathrm{m}$.

The grains were then poured slowly into the groove. Special attention was paid to ensure that the groove was filled by a single mono layer of grains. A microscope slide was finally placed on the top of the groove and sealed with silicon. After a drying period of a few hours, a filter made of fabric pocket of $50 \mu \mathrm{m}$ mesh containing sandstone grains was placed between the end of the channel and the outlet connexion to prevent the grains from leaving the slot without obstructing the flow. Tubes allowing for the fluids injection in the 


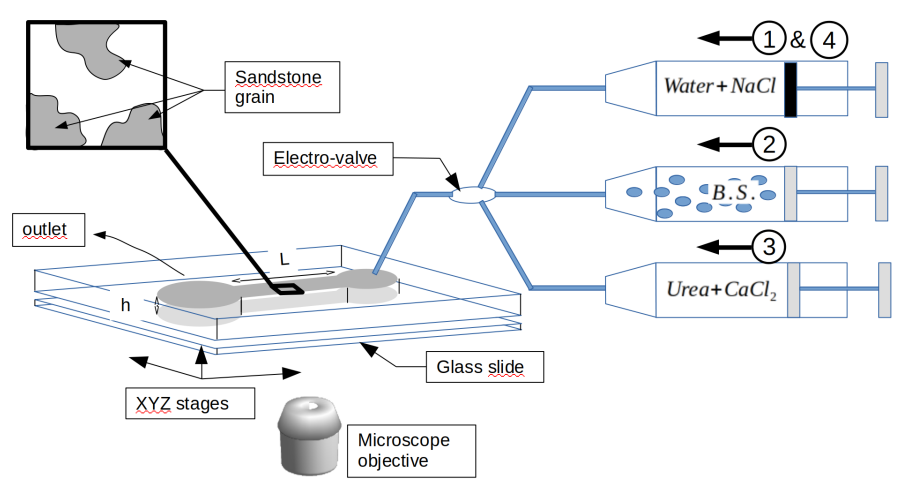

a)

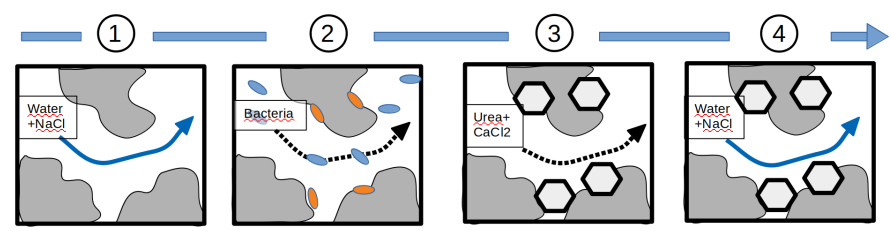

b)

Fig. 1 a) Schematic views of the experimental set-up. The sandstone grains are placed in the canal of length $\mathrm{L}=35 \mathrm{~mm}$, width $\mathrm{w}=0.5 \mathrm{~mm}$ and height $\mathrm{h}=0.1 \mathrm{~mm}$. A computer-controlled electro-valve allows to switch between three different solutions: a NaCl-water mixture, a suspension of bacteria (BS) and the calcifying solution (Urea $+\mathrm{CaCl}_{2}$ ). b) Illustration of the four steps of the process. Step 1: Injection of the $\mathrm{NaCl}$ solution. Step 2: Injection of the suspension of bacteria (blue ellipsoid) and the adhesion of some (orange ellipsoid). Step 3: Injection of the calcifying solution and formation of calcite shells around the bacteria (represented by hexagons). Step 4: The medium is flushed again with the $\mathrm{NaCl}$ solution.

channel were installed. The inlet was connected to a set of three computercontrolled neMESYS ${ }^{\circledR}$ pumps. The glass syringes (Hamilton ${ }^{\circledR}$ ) of $1 \mathrm{~mL}$ were mounted on the pumps. They contained respectively water with salt, the bacterial solution and the calcifying solution. The computer controlled the flow rate in each of the pumps separately and the valves.

The flow cell was placed under an inverted microscope Leica ${ }^{\circledR}$ DMI 6000 with the microscope slide placed down. A computer-controlled $x-y$ translation table enabled the positioning at various locations along the canal. Sequences of images were recorded using a Hamamatsu ${ }^{\circledR}$ Orcade Flash 4 camera with a frame rate that was adapted to the flow conditions. Two microscope objectives were used. The $\times 10$ allowed observation over a field of about 1.3 by $1.3 \mathrm{~mm}^{2}$ and its depth of field is $30 \mu \mathrm{m}$. The $\times 63$ is a long-distance objective with a field of view of 206 by $206 \mu \mathrm{m}^{2}$ with the capacity to take images at the scale of a single grain. Its field of depth is about $4 \mu \mathrm{m}$. All observations are done under bright-field conditions.

The homogeneity of the filling of the canal was tested by measuring the number of grains and the porosity from images regularly taken with the $\times 10$ objective throughout the length of the channel. The procedure used to deter- 


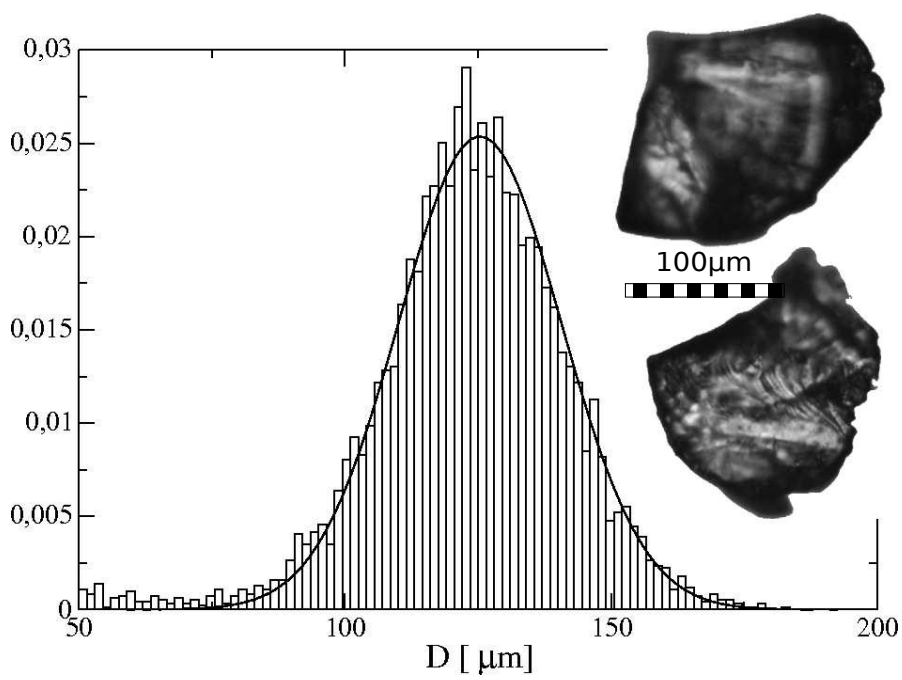

Fig. 2 Histogram of the diameter of more than 19000 grains determined with the MorphologiG3 analyzer. The solid line is the adjustment by a Gaussian function of the data. The average diameter of the grain is $125 \mu \mathrm{m}$ with a standard deviation $\sigma=15 \mu \mathrm{m}$. Insert: Example of images of grains obtained with a $\times 10$ objective.

mine the porosity $\theta$ from images is described in the Online Resource 2. The procedure was repeated on other samples, and as for the example shown in the Online Resource 2, no trends of the variation of the porosity with the distance is identified. We then, prior to the injection of the bacterial solution, took pictures at four different positions: a first one close to the inlet, two in the canal and one in the vicinity of the outlet. Using the same image treatment as described in the Online Resource 2, we determined the porosity for each position. The value of the porosity assigned to each sample - and given in Tab. 1 - is the average of the porosities measured on the different locations.

2.1 Fluid preparation, induced precipitation kinetic and injection protocol

Bacterial suspension: $B S$

The strain of Sporosarcina pasteurii DSM 33 used in the present study was originally purchased from Leibniz Institute DSMZ (German Collection of Microorganisms and Cell Cultures). The lyophilisate was stored in a freezer at an average temperature of $-20^{\circ} \mathrm{C}$. One gram was taken from the lyophilisate and diluted in a liter of mineral water from the Cristaline ${ }^{\circledR}$ spring containing a certain quantity of dissolved ions. The ionic force of the mineral water is $I \sim 0.35 \mathrm{mM}$. The solution was finally stirred for $30 \mathrm{~min}$ with a magnetic stirrer before its use. Optical density measurements at $600 \mathrm{~nm}$ indicated that the solution contained about $0.3 \times 10^{8}$ bact. $/ \mathrm{mL}$. The bacteria were not motile 


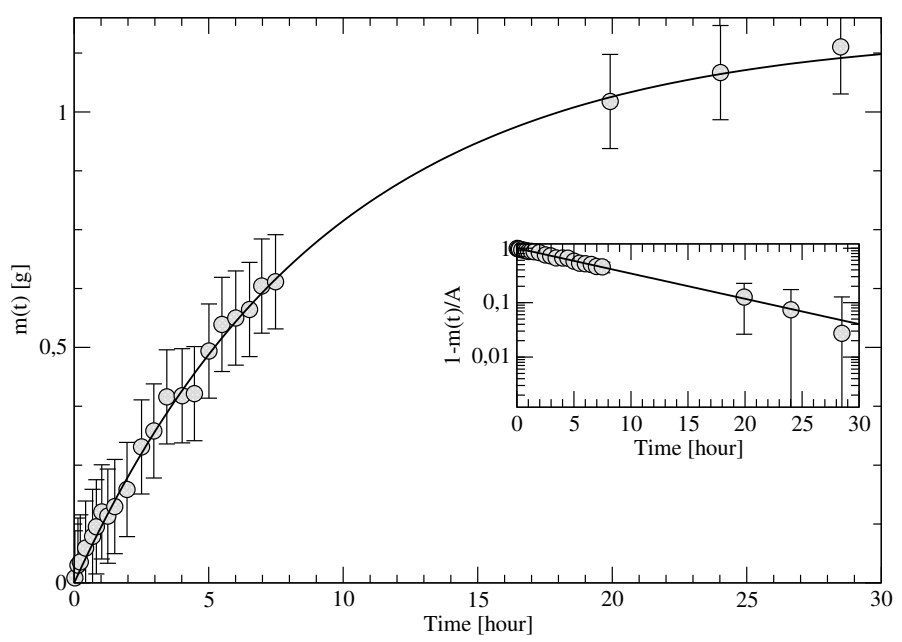

Fig. 3 Circles show the mass, $m(t)$, in gram of calcite produced by the mixing of $1 \mathrm{~mL}$ bacterial suspension with $3 \mathrm{~mL}$ of calcifying solution as function of time. Solid line: adjustment of the data by the function : $m(t)=A\left(1-e^{-k_{\text {calc. }}{ }^{t}}\right)$. The fit gives $k_{\text {calc. }}=0.107 \mathrm{~h}^{-1}$ corresponding to a time of reaction of about 10 hours. The inset shows $1-\frac{m(t)}{A}$ as function of time on a lin-log scale. The slope of the solid line is $-k_{\text {calc. }}$.

but due to the thermal agitation they diffused with a coefficient of diffusion $D_{m} \sim 0.3 \mu \mathrm{m}^{2} . \mathrm{s}^{-1}$.

\section{Calcifying solution: $C S$}

This fluid was prepared from an equimolar mixture of $1.4 \mathrm{~mol} / \mathrm{L}$ of urea $(\sim$ $84 \mathrm{~g} / \mathrm{L})$ and calcium chloride $\left(\mathrm{CaCl}_{2}\right)(\sim 155 \mathrm{~g} / \mathrm{L})$. All chemical products were purchased from VWR ${ }^{\circledR}$ France. The contact of the urease produced by the bacteria with urea induces its hydrolysis. This leads to the production of $\mathrm{NH}_{4}^{+}$ and an increase in $\mathrm{pH}$. The $\mathrm{pH}$ rises trigger the conditions for the carbonate supersaturation which induces the formation of a carbonate shell around the bacteria.

To charaterize the kinetics of the calcification, 24 tubes each containing $1 \mathrm{~mL}$ of BS and $3 \mathrm{~mL}$ of CS were prepared and continuously agitated. At regular times, a tube was chosen and the calcite was separated from the fluid by flowing it through a paper filter. Material thus collected was weighed. The evolution of the weight as function of time is shown in Fig.3. The mass of calcite produced increased with time and seemed to saturate at a value close to $1.2 \mathrm{~g}$. Following the studies of Handley et al [19] and Lauchnor et al [20] on bio calcification, our data were adjusted using a first order kinetic equation (See solid line in Fig.3). The best fit was obtained for a reaction rate of $k_{\text {calc. }}=0.107 \mathrm{~h}^{-1}$. In all the experiments reported in the present study the calcifying solution was left for more than one day allowing each bacteria to produce a calcite shell.

Some calcite grains were collected and observed under the microscope and images were acquired. The image treatment consisted in a threshold of the grey 
level performed using ImageJ. A python procedure was then used to determine the size of each closed white area. The surfaces were found to range between 180 and $220 \mu \mathrm{m}^{2}$ corresponding to calcite grains of radius ranging between 7 and $9 \mu \mathrm{m}$.

Fluid used to saturate the pores

We used saline water for this operation. The concentration in salt was similar to the $\mathrm{NaCl}$ concentration used to prepare the bacterial suspension. This fluid was initially slowly injected into the porous medium at a flow rate of $1 \mu \mathrm{L} . \mathrm{s}^{-1}$ so that a complete saturation of the pore volume was obtained in about $18 \mathrm{~min}$. The solution was kept for about $30 \mathrm{~min}$ inside the pores before the injection of the suspension started.

In this work, we varied the duration of the injections between 15 and $120 \mathrm{~min}$ corresponding to an injection of 1 to 10 pore volumes. The influence of the $\mathrm{NaCl}$ concentration was also studied. After the injection of the bacterial solution, the calcifying solution was injected at a constant flow rate of $0.5 \mu \mathrm{L} . \mathrm{s}^{-1}$ for over a day so as to ensure a good calcification of the bacteria. Table 1 details the experimental conditions of the present study.

\begin{tabular}{cccccc}
\hline Exp. & $\mathrm{NaCl}[\mathrm{g} / \mathrm{L}]$ & $\mathrm{I}[\mathrm{mM}]$ & $v_{f}\left[\mu \mathrm{m} . \mathrm{s}^{-1}\right]$ & $t_{\text {inj }}[\mathrm{min}]$ & $\theta \pm \delta \theta$ \\
\hline 1 & 3 & 51 & 200 & 10 & $0.47 \pm 0.07$ \\
2 & 3 & 51 & 200 & 30 & $0.47 \pm 0.06$ \\
3 & 3 & 51 & 200 & 45 & $0.47 \pm 0.06$ \\
4 & 3 & 51 & 200 & 60 & $0.48 \pm 0.08$ \\
5 & 3 & 51 & 200 & 120 & $0.44 \pm 0.04$ \\
6 & 3 & 51 & 200 & 20 & $0.47 \pm 0.06$ \\
7 & 5 & 86 & 200 & 20 & $0.46 \pm 0.05$ \\
8 & 6 & 102 & 200 & 45 & $0.42 \pm 0.06$ \\
9 & 10 & 170 & 200 & 20 & $0.47 \pm 0.07$ \\
\hline 10 & 3 & 51 & 220 & 240 & 0.37 \\
11 & 10 & 170 & 219 & 97 & 0.38 \\
12 & 20 & 340 & 219 & 97 & 0.37 \\
\hline
\end{tabular}

Table 1 Second row: quantity of $\mathrm{NaCl}$ in $g / L$ mixed with the bacterial solution and used to flush the channels. $I$ ionic strength, $v_{f}$ filtration velocity and $t_{i n j}$ injection time in minute of the suspension of bacteria. $\theta$ : Average porosity estimated from image analysis over the set of images. $\delta \theta$ : largest absolute difference between the average porosity and the set of porosities measured analyzed. Details about the method used to obtain $\theta$ are provided in the Online Resource 2. Exp. 10 to 12 correspond to column experiments. For these experiments, $\theta$ was obtained from the volume of solution used to saturate the column.

\subsection{Calcite crystal detection}

After the experiments, at least 4 sets of images were taken at different positions along the channel. A set of images corresponds to images acquired at the same horizontal position $(\mathrm{x}, \mathrm{y})$ but at different vertical positions $\mathrm{z}$. The 
displacement is done by automatically moving the focal plane of the $10 \times$ objective from the bottom to the top surfaces. Each image contained between 100 and 150 sandstone grains. The crystals that had grown from the bacteria were clearly identifiable. Fig.4c) is a zoom in on the picture shown in Fig.4a). The crystals that had grown on the sandstone grains are easy to spot. The difference in the refractive index between the sandstone and the calcite explains the facility of the identification of the crystals. We also note that they have a similar size to the calcite grains (See Sec.2.1). Video made from images taken at different vertical positions are presented in Online Resource 3 and 4. To properly visualize the crystals, we zoomed in on a grain. The first video (Online Resource 3) shows a grain observed in the flow cell used in Exp.1. The Online Resource 4 shows a grain which had stayed for a longer time (one hour instead of ten minutes) in contact with the bacterial suspension. The number of crystals observed is clearly larger on the last video demonstrating that more bacteria have adhered to the surface of the grain. The number of crystals formed was determined by the method described below:

An operator opens each set of images with an image processing software, zooms in on each part of the image and manually affixes a red point on each crystal. The total number of detected crystals is then easy to determine. Knowing the number of grains on the image, the average number of crystals on each grain can be calculated. The uncertainty of the measurement is estimated as the standard deviation of the average number measured on the images obtained.
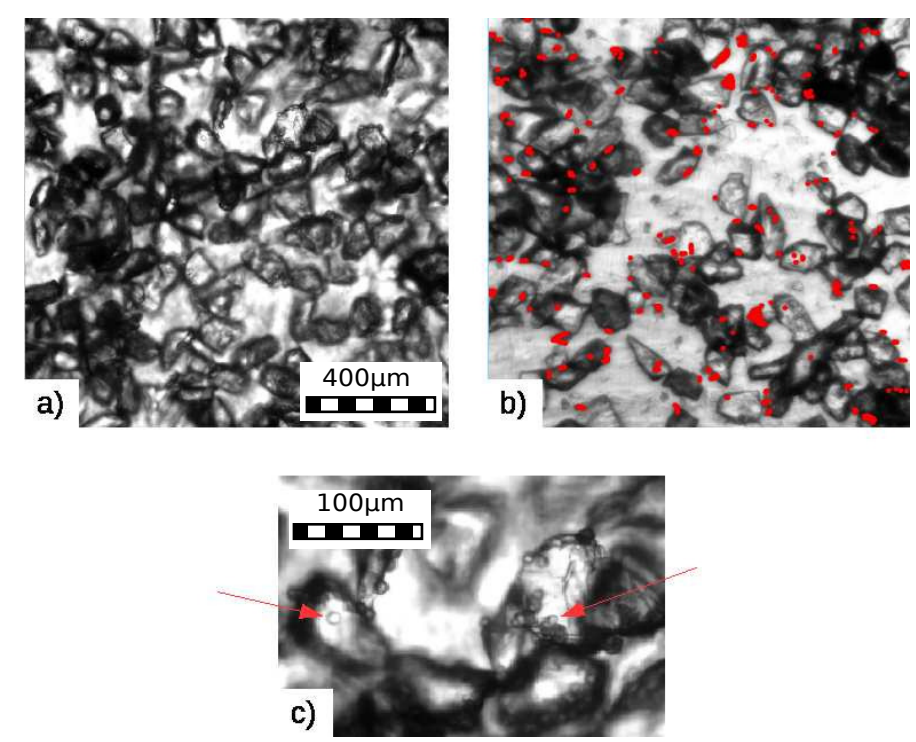

Fig. 4 a) Example of image showing sandstone grains after an experiment. This image was taken with a $\times 10$ objective. b) Image obtained after the detection of the calcite crystals. The red spots show the crystals detected. c) Close-up view of the sandstone grains. The red arrows indicate some of the crystals. Video at the grain scale are available in the Online Resources section. 


\section{Experimental results}

3.1 Experiments in the microfluidic channel

In a first set of experiments, we studied the influence of the injected volume of bacterial suspension $n$ on the number of crystals grown. The $\mathrm{NaCl}$ concentration in the bacterial suspension (here $3 \mathrm{~g} / \mathrm{L}$ ) and the filtration velocity $\left(\mathrm{v}_{\mathrm{f}}=200 \mu \mathrm{m} . \mathrm{s}^{-1}\right)$ were fixed.

The average number of crystals spotted per grain as function of the injection time is represented in Fig. 5. All data, within the error bars, fall on a straight line (solid line in Fig. 5 ) of slope $\sim 0.15$ bact/min per grain.

Additional experiments with higher ionic strengths were also performed. The average number of crystals measured under these three new conditions are also shown in Fig. 5 and represented by square, triangle and diamond. We see that increasing the ionic strength while keeping the time of injection constant resulted in more crystal formation.

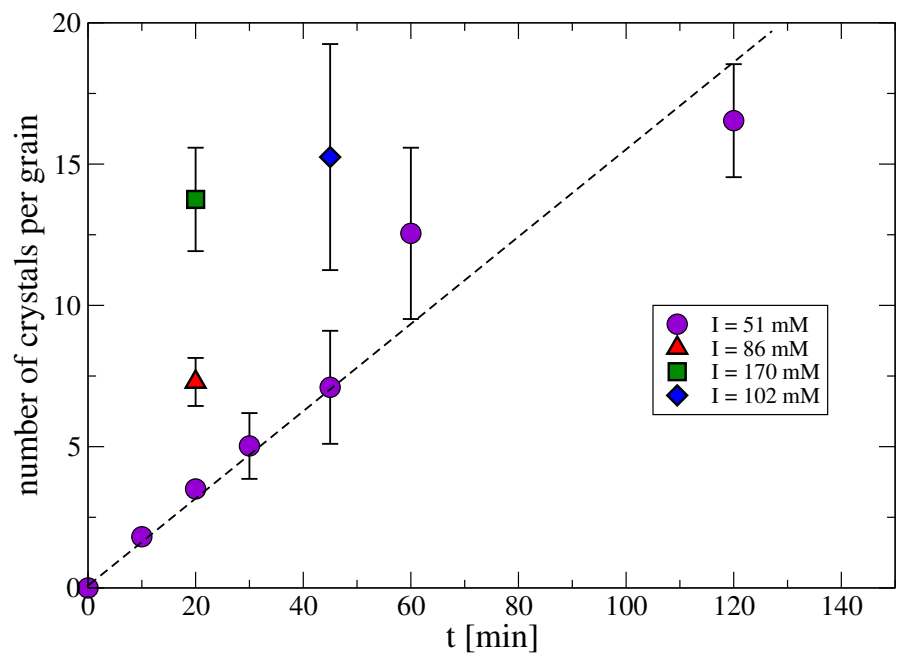

Fig. 5 Average number of calcite crystals observed as function of the injection time of the bacterial solution. Vertical bars are the fluctuations of the number of detected crystals. Filled circles are experiments performed at $\mathrm{I}=51 \mathrm{mM}$ (Exp. $1-6$ in Tab. 1). Triangle, square and diamond correspond respectively to $\operatorname{Exp} .7(\mathrm{I}=86 \mathrm{mM}), 8(\mathrm{I}=102 \mathrm{mM})$ and $9(\mathrm{I}=170 \mathrm{mM})$ in Tab. 1). Solid line: linear fit of the filled circles for injection times less or equal to $60 \mathrm{~min}$. The slope of the dotted line is $\sim 0.15$ bact. $\min ^{-1}$ per grain.

Each crystal observed on the surface of grains originates from a bacteria that left the suspension and adhered to the grain surface. Assuming that the grains are spherical with a diameter of $63 \mu \mathrm{m}$, the volume of a single grain is close to $1 n L$. The concentration of bacteria adsorbed per unit of volume is then $s=n / 10^{-6}$. Using Eq.(4), we see that the adsorption rate $\kappa^{+}$can be estimated from the porosity $\theta$, the concentration of bacteria in the suspension 
$c_{0}$, the time $t$ and the number of crystals detected as:

$$
\kappa^{+}=\frac{1-\theta}{\theta} \frac{n}{10^{-6} c_{0} t}
$$

Figure 6 shows the values of the adhesion rate deduced from the experimental
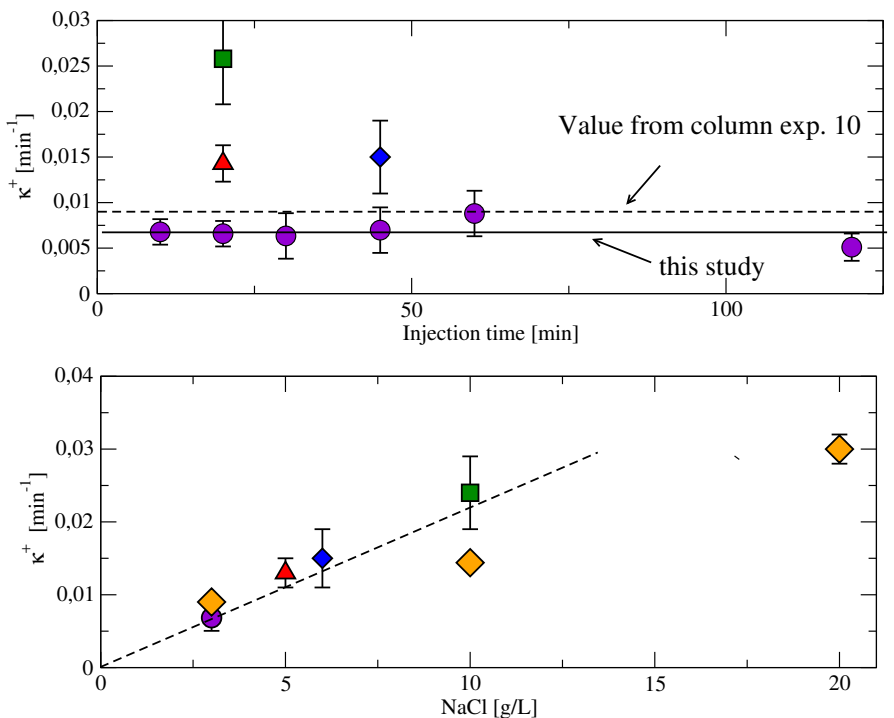

Fig. 6 Top figure: Adhesion rate $\kappa^{+}$in $\min ^{-1}$ as function of the time of injection of the calcifying solution. Filled circles: $I=51 \mathrm{mM}$ and different injection durations. Triangle, square and diamond correspond respectively to $\operatorname{Exp} .7(\mathrm{I}=86 \mathrm{mM}), 8(\mathrm{I}=102 \mathrm{mM})$ and 9 $(\mathrm{I}=170 \mathrm{mM})$ in Tab. 1. Horizontal dotted line are values measured using packed-bed column experiments with $I=51 \mathrm{mM}(3 \mathrm{~g} / \mathrm{L})$. Bottom figure: Adhesion rate $\kappa^{+}$as function of the ionic strength. Diamonds: Packed-bed column experiments. Circle, triangle, diamond and square: Present study. Dotted line: Linear fit of slope 0.002 of the data. All experiments are for $v_{f} \simeq 200 \mu \mathrm{m} / \mathrm{s}$. The value for the circle was obtained by averaging the adhesion rates measured for different injection times but same I (Exp.1 - 6 in Tab. 1).

measurements using Eq.(5). The values are all between 0.005 and $0.025 \mathrm{~min}^{-1}$ corresponding to a typical absorption time between 40 and $200 \mathrm{~min}$.

\subsection{Column experiments}

To support our results, we performed additional measurements on columns. Details concerning the method are given in [21]. To that end, we used three PVC tubes of length $\mathrm{L}=20 \mathrm{~cm}$ and diameter $6.8 \mathrm{~cm}$ that we filled with sandstone grains. The columns were then closed by plugs that have two uses: they both hold the grains in position and allow the fluids to flow homogeneously 
over all the section of the column. The column was first saturated with water. The volume of water in the column was used to determine the porosity of the grain packing. For all three experiments, the porosity was close to 0.38 . The bacterial suspension was then injected during $97 \mathrm{~min}$ at a velocity $\mathrm{v}_{\mathrm{f}} \simeq 200 \mu \mathrm{m} . \mathrm{s}^{-1}$ and the optical density (OD) of the suspensions at the inlet $\left(\mathrm{OD}_{\text {in }}\right)$ and at the outlet $\left(\mathrm{OD}_{\text {out }}\right)$ were recorded during the entire duration of the experiments [21]. After the breakthrough of the bacterial suspensions, the OD slowly tended to a constant value with a small but constant positive slope. The relation between bacterial concentration and OD was first determined in calibration experiments. We found that OD and bacterial concentration were proportional in the range of concentration used. The ratio between the signal measured at the inlet and at the outlet could then be used to determine the number of bacteria left in the column. The ratio was here estimated from the value of the signal after the injection of $552 \mathrm{~mL}$ corresponding two pore volumes [21].

From Eq.(5), we see that $\kappa^{+}$can be easily obtained from the ratio of the bacterial concentration measured at the inlet and at the outlet or from the ratio of the OD signals by using the relation:

$$
\kappa^{+}=\frac{v_{f}}{\theta L} \ln \left(\frac{\mathrm{OD}_{\text {in }}}{\mathrm{OD}_{\text {out }}}\right)
$$

The values measured for three different ionic strengths are represented by diamonds in Fig.6. They are quantitatively very close to the values obtained with the microfluidic experiments and the same linear dependence with the ionic strength is found.

\subsection{Distribution of the crystals on the sandstone}

We will now take advantage of the possibility offered by our method to determine the position of the crystals to study their statistical repartition on the grains. To do so, we counted the crystals respectively $n_{u}$ and $n_{d}$ formed on the upstream and downstream sides of the grains. The method followed to determine $n_{u}$ and $n_{d}$ is detailed in Fig.7a). Each grain was enclosed in a rectangle which was separated in two areas of equal surface. The crystals were then counted following the same procedure as described previously. The ratio $\frac{n_{u}}{n_{d}}$ is shown in Fig.7b for the different experimental conditions.

We observed that there are always more crystals on the side facing the flow. The difference between the two sides however does not exceed $20 \%$. For a fixed ionic force $(I=51 \mathrm{mM})$, the ratio seems to be constant with values ranging between 1.1 and 1.2 except for the highes injection time considered. In this case, the ratio is close to 1 . We note also that the ionic force does not seem to have an influence on the difference between upstream and downstream sides. 


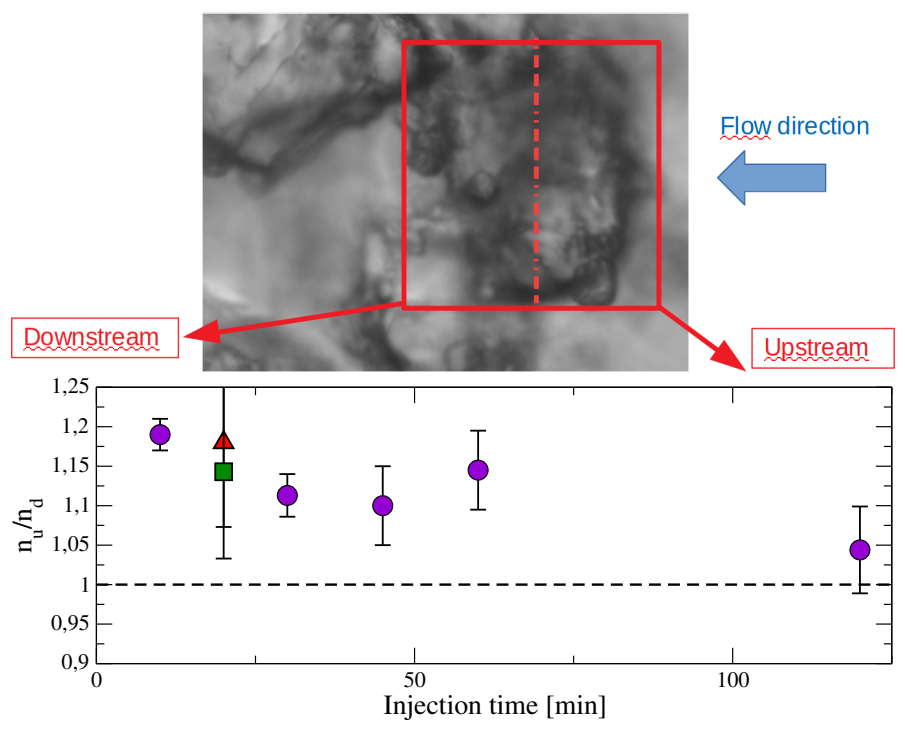

Fig. 7 Top figure: Illustration of the method used to obtain $n_{u}$ and $n_{d}$. The flow is from right to left. A rectangle (in red) is drawn around each grain. The rectangle is divided in two halves of equal area. The number of crystals in each half gives $n_{u}$ and $n_{d}$. Bottom figure: Ratio $\frac{n_{u}}{n_{d}}$ as function of the time of injection of the bacteria. Circles, triangle and square are respectively for $I=51,102$ and $170 \mathrm{mM}$ (see Tab.1 for details). The horizontal dotted line shows $\frac{n_{u}}{n_{d}}=1$.

\section{Discussion}

Column experiments are currently the preferred tool to estimate transport parameters like hydrodynamic dispersion, diffusion, absorption or degradation of fluids through porous medium. This technique is reputed flexible and cheap, compared to field experiments and easy to manage (the boundary and flow conditions can be controlled). In the context of MICP, column experiments provide an estimate of the adhesion rate of bacteria, $\kappa^{+}$, as function of the flow and physico-chemical conditions. For instance, in the present study, this technique was used to measure $\kappa^{+}$for different ionic strengths. Yet to realize one single experiment about 10 liters of calcifying solution and 10 liters of bacterial suspension were prepared, and hours were needed to inject the fluids. They were the principal source of test costs. In comparison, only $10 \mathrm{~mL}$ of each solution were needed with the microfluidic experiments and yet still enabled us to obtain the absorption rate $\kappa^{+}$. In the column experiments, the profile of concentration in absorbed bacteria was supposed to decrease exponentially as predicted by the filtration theory (See Eq.(5)) with a decay occurring over a typical distance $\lambda=\frac{v_{f}}{\kappa^{+} \theta}$. For the conditions used in this study, $\lambda$ was of the order of few hundreds of centimeters and was of the order of the the column length $\mathrm{L}=20 \mathrm{~cm}$. Measuring the concentration drop $c_{0} / c(L)$ between the inlet and the outlet to obtain $\kappa^{+}$is then a relevant method. On the contrary, the 
length of the microfluidic cell was shorter than $\lambda$ and the absorption rate could not be estimated by the same technique. In this case, we used an alternative method based on the counting of the number of calcite grains formed. Using Eq.(5), we were then able to successfully measure $\kappa^{+}$.

With both techniques, we observed that $\kappa^{+} \propto I$ for $I$ between 50 and $340 \mathrm{mM}$. The increase of the absorption rate with the ionic strength was also observed with other types of bacteria like Pseudomonas Aeroginosa [22], Pseudomonas fluorescens [10], Alcaligenes paradoxu [23], Escherichia coli [8] and for other unclassified wild type bacteria $[24,25]$. These observations were consistent with the DLVO theory $[7,8,26]$ that predicts a screening of the repulsive force, due to the negative surface charge of the grains and of the bacteria by the ions in the solution, that result in an increase of the adhesion rate. All conditions are met here so that Van der Waals forces act in the adhesion process [27]: The body of the bacteria is negatively charged [28] as the sandstone [29] and the density of ions in solution is sufficiently high so that a double layer of charges is formed favoring induced dipoles and adhesion [16]. As a consequence, we deducted a strategy to reduce the injected volume of solution by using a higher concentration of salt.

Finally, for long injection times or large injected volumes, a small decrease of the adhesion rate was observed. Similar observations were reported in studies examining the transport of E-coli in soil [30] or Sporosarcina pasteurii in sandstone [9]. They attributed this attenuation to the release of bacteria from the grain. This effect could be clearly identified on the breakthrough curves that have a slight tendency to increase over a long period of time. This was also observed on our column experiments. Release of the bacteria might thus be an additional phenomena to consider to model MICP for long injection time or high ionic force. Yet, two other phenomena can be mentioned to explain the reduction of the absorption rate. The lysis and the degradation of the proteins of the bacteria are factors that can limit the formation of calcite over long periods of time. Moreover, a reduction of the absorption rate can come from the finite number of available absorption sites on the grain. Visualizations at grain scale on experiments performed for longer exposure time to bacteria or performed at larger ionic forces than the conditions reported in this article revealed that a large proportion of grains are embedded in crystals. For example, one grain observed for $\mathrm{I}=255 \mathrm{mM}$ for an injection time of $45 \mathrm{~min}$ is shown in the Online Resource 5. We can suppose that the presence of the calcite grains modifies the conditions for absorption which result in a reduction of the absorption rate. If this is correct, the upstream side of the grains should reach faster the saturation than the downstream side of the grains. The number of bacteria on the downstream side, $n_{d}$, will continue to grow while the number of bacteria on the upstream side, $n_{u}$, will plateau to a constant value. As a consequence, the ratio $\frac{n_{u}}{n_{d}}$ will then tend to 1 as indeed observed in Fig.7. This information deduced from observation at the grain scale supports the idea of a decrease of the adhesion rate with time due to the saturation of the number of absorption sites to the detriment of a model based on desorption kinetics. 


\section{Conclusion and perspectives}

This study demonstrates that macroscopic quantities like the adsorption rate can be accurately and reliably obtained from measurements done at the scale of a few thousands of grains. The method is also shown to provide information about the spatial repartition of the crystals on the grains that future work could relate to hydro and mechanical properties of the sample. Even if a lot has to be done to automate the image treatment and to speed-up the analysis, the major benefit of the method as compared to packed-bed column or field experiments is the ease with which the experimental conditions can be changed. This opens the possibility to screen the influence of parameters like the flow and the physicochemical conditions on the MICP and might prove very useful to optimize the process or to derive laws that can be implemented in numerical models.

Future studies will, for instance, consider the effect of the type of ions put in the solutions on the adhesion but also the role of the flow rate on the repartition of the crystals on the grains. Simultaneously, the surface charge of the bacteria and of the sandstone could be characterized by, for example, zeta potential measurements to quantify the role of electrokinetic on adhesion.

Finally, thanks to the transparency of the set-up, bacteria can be tracked during their transport and this opens the possibility to observe the mass exchange between the fluid and the grains. By way of example, a video of the bacteria suspension at the scale of few grains is proposed on the Online Resources 6 and 7 . From the video, we were able to track bacteria and reconstruct their trajectories (See Online Resources 8). Among all the bacteria, some moving to the surface of the grains can be traced, opening up the possibility to study the dynamics of attachment of bacteria at the microscale.

Acknowledgements We acknowledge support by "Investissements d'Avenir" LabEx PALM (ANR-10-LABX-0039-PALM) and by the French National Research Agency (ANR Bacflow AAPG 2015). The authors wish to thank R. Pidoux for his help in the design and realization of the experimental set-up, C. Manquest for his help with the MorphologiG3 anaylser and Solétanche-Bachy for its financial support.

\section{References}

1. Dadda, A., Geindreau, C., Emeriault, F. et al.: Characterization of microstructural and physical properties changes in biocemented sand using 3D X-ray microtomograph. Acta Geotech. 12: 955 (2017). https://doi.org/10.1007/s11440-017-0578-5

2. De Muynck, W., De Belie, N., Verstraete, W.:Microbial carbonate precipitation in construction materials: A review. Ecol. Eng., Special Issue: BioGeoCivil Engineering 36, 118-136 (2010). https://doi.org/10.1016/j.ecoleng.2009.02.006

3. Rodriguez-Navarro, C., Rodriguez-Gallego, M., Ben Chekroun, K., Teresa GonzalezMuñoz, M.: Conservation of Ornamental Stone by Myxococcus xanthus Induced Carbonate Biomineralization. Appl. Environ. Microbiol. 69, 2182-93 (2003). https://doi.org/10.1128/AEM.69.4.2182-2193.2003

4. Harvey, R.W., Garabedian, S.P.: Use of colloid filtration theory in modeling movement of bacteria through a contaminated sandy aquifer. Environ. Sci. Technol. 25, 178-185 (1991). 
5. Hornberg, G.M., Mills, A.L., Herman, J.S.: Bacterial Transport in Porous Media Evaluation of a Model Using Laboratory Observation. Water Resour. Res. 28, 915-938 (1992).

6. Schijven, J.F., Medema, G., Vogelaar, A.J., Hassanizadeh, S.M.: Removal of microorganisms by deep well injection. J. Contam. Hydrol. 44, 301-327 (2000).

7. Logan, B.E., Hilbert T.A., Arnold R.G.: Removal of bacteria in laboratory filters: Models and Experiments. Wat. Res. 27(6):955-962 (1993).

8. Redman, J.A., Walker, S.L., Elimelech, M.: Bacterial Adhesion and Transport in Porous Media: Role of the Secondary Energy Minimum. Environ. Sci. Technol. 38, 1777-1785 (2004). https://doi.org/10.1021/es0348871

9. Tobler, D., Cuthbert, M., Phoenix, V.: Transport of Sporosarcina pasteurii in sandstone and its significance for subsurface engineering technologies. Appl. Geochem. 42 (2014). https://doi.org/10.1016/j.apgeochem.2014.01.004

10. Jewett, D.G., Hilbert, T.A., Logan, B.E., Arnold, R.G., Bales, R.C.: Bacterial transport in laboratory columns and filters: Influence of ionic strength and $\mathrm{pH}$ on collision efficiency. Water Res. 29, 1673-1680 (1995). https://doi.org/10.1016/0043-1354(94)00338-8

11. Harkes, M.P., van Paassen, L.A., Booster, J.L., Whiffin, V.S., van Loosdrecht, M.C.M: Fixation and distribution of bacterial activity in sand to induce carbonate precipitation for ground reinforcement. Ecol. Eng. 36 112-117 (2010).

12. Bai, Y., Guo, X., Li, Y., Huang, T.: Experimental and visual research on the microbial induced carbonate precipitation by Pseudomonas aeruginosa. AMB Express 7 (2017). https://doi.org/10.1186/s13568-017-0358-5

13. Guckenberger, D. J., de Groot, T. E., Wan, A. M. D., Beebe, D. J., Young, E. W. K., : Micromilling: a method for ultra-rapid prototyping of plastic microfluidic devices. Lab Chip 15(11), 2364-2378 (2015). http://dx.doi.org/10.1039/C5LC00234F

14. Boschan, A., Auradou, H., Chertcoff, R., Ippolito, I., Hulin, J.P.: Miscible displacement fronts of shear thinning fluids inside rough fractures. Water Resour. Res. 43, W03438 (2007). doi:10.1029/2006WR005324.

15. Liu, Y., Wang, J.-C., Ren, L., Tu, Q., Liu, W.-M., Wang, X.-Q., Liu, R., Zhang, Y.R., Wang, J.-Y.: Microfluidics-based assay on the effects of microenvironmental geometry and aqueous flow on bacterial adhesion behaviors. J. Pharm. Sci. 1(3), 175-183 (2011). doi:10.1016/j.jpha.2011.06.001

16. Auset, M., Keller, A.A.: Pore-scale visualization of colloid straining and filtration in saturated porous media using micromodels. Water Resour. Res. 42, W12S02 (2006). https://doi.org/10.1029/2005WR004639

17. Yutaka, Y., Jen, N., Stocker, R., Rusconi, R.: Microfluidic Studies of Biofilm Formation in Dynamic Environments. Journal of Bacteriology 198(19), 2589-2595 (2016). 10.1128/JB.00118-16

18. Nadell, C., Drescher, K., Foster, K.: Spatial structure, cooperation and competition in biofilms. Nat. Rev. Microbiol. 14, 589âĂŞ600 (2016). doi:10.1038/nrmicro.2016.84

19. Handley-Sidhu, S., Sham, E., Cuthbert, M.O., Nougarol, S., Mantle, M., Johns, M.L. Macaskie, L.E., Renshaw, J.C.: Kinetics of urease mediated calcite precipitation and permeability reduction of porous media evidenced by magnetic resonance imaging. Int. J. Environ. Sci. Technol. 10, 881-890 (2013). https://doi.org/10.1007/s13762-013-0241-0

20. Lauchnor, E.G., Topp, D.M., Parker, A.E., Gerlach, R.: Whole cell kinetics of ureolysis by Sporosarcina pasteurii. J. Appl. Microbiol. 118(6), 1321-32 (2015). doi:10.1111/jam.12804.

21. Lépine L., Sapin L., Gutjahr I., Esnault Filet A., 2019. Numerical Modeling of Biocalcis injection method for ground improvement at industrial scale. under preparation.

22. Choi, N.-C., Kim, D.-J., Kim, S.-B.: Quantification of bacterial mass recovery as a function of pore-water velocity and ionic strength. Res. Microbiol. 158, 70-78 (2007). https://doi.org/10.1016/j.resmic.2006.09.007

23. Li, Q., Logan, B.E.: Enhancing bacterial transport for bioaugmentation of aquifers using low ionic strength solutions and surfactants. Water Res. 33, 1090-1100 (1999). https://doi.org/10.1016/S0043-1354(98)00291-7

24. Fontes, D.E., Mills, A.L., Hornberger, G.M., Herman, J.S.: Physical and chemical factors influencing transport of microorganisms through porous media. Appl. Environ. Microbiol. 57, 2473-2481 (1991). 
25. Bolster, C.H., Mills, A.L., Hornberger, G.M., Herman, J.S.: Effect of surface coatings, grain size, and ionic strength on the maximum attainable coverage of bacteria on sand surfaces. J. Contam. Hydrol. 50, 287-305 (2001). https://doi.org/10.1016/S0169$7722(01) 00106-1$

26. Tufenkji, N., Elimelech, M.: Correlation Equation for Predicting Single-Collector Efficiency in Physicochemical Filtration in Saturated Porous Media. Environ. Sci. Technol. 38, 529-536 (2004). https://doi.org/10.1021/es034049r

27. Jacobs, A., Lafolie, F., Herry, J.M., Debroux, M.: Kinetic adhesion of bacterial cells to sand: Cell surface properties and adhesion rate. Colloids Surf. B Biointerfaces 59, 35-45 (2007)

28. Keykha, H.A., Huat, Bujang B. K., Asadi, Afshin, Mohsen, Z., Satoru, K.: Electrokinetic properties of pasteurii and aquimarina bacteria. Environmental Geotechnics 2(3), 181-188 (2015). https://doi.org/10.1680/envgeo.13.00072

29. Shehata, A.M., Nasr-El-Din, H.A.: Zeta: Potential Measurements: Impact of Salinity on Sandstone Minerals. SPE International Symposium on Oilfield Chemistry, (2015). https://doi.org/10.2118/173763

30. Bradford, S.A., Simunek, J., Walker, S.L.: Transport and straining of E. coli O157:H7 in saturated porous media. Water Resour. Res. 42, (2006). https://doi.org/10.1029/2005WR004805 